\title{
MRI Diagnosis of Accessory Soleus Muscle: A Case Report and Review of the Literatures
}

\section{Jun Zhang, Dapeng Hao*, Chuanyu Zhang and Shaohua Wang}

Department of Radiology, The Affiliated Hospital of Qingdao University, China

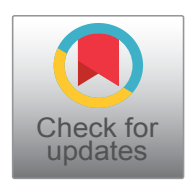

*Corresponding author: Dapeng Hao, Ph.D, MD, Department of Radiology, The Affiliated Hospital of Qingdao University, Qingdao, 266003, China, Tel: 86-18661802582

\begin{abstract}
The accessory soleus muscle is a rare anatomical variant that usually occurs in adolescents or young adults. And it may manifest as an exertional ankle pain and swelling or as an asymptomatic posteromedial mass. However sometimes it may be mistaken as a soft tissue tumor at the ankle. The purpose of this study is to heighten awareness about the existence of accessory soleus muscle in a swelling at the posteromedial aspect of the ankle and to reduce the failure to recognize this muscle in MRI.
\end{abstract}

\section{Keywords}

Accessory soleus muscle, Congenital anatomical variant, MRI diagnosis, Ankle

\section{Introduction}

The accessory soleus muscle is a rare congenital anatomic variant, whose incidence is estimated to occur in $0.7 \%$ to $5.5 \%$ of the general population [1-3]. Clinically, if the muscle belly is large, the accessory soleus muscle may appear as a soft tissue prominence posterior to the medial malleolus. It will become pain and swelling in the posteromedial aspect of the leg with activity. Sometimes it can be misdiagnosed to other diseases, such as lipoma, ganglion, hemangioma, sarcoma and synovioma [1,2]. Radiological investigations include plain radiographs, US, CT and MRI [4-7]. However, MRI has characteristic diagnostic value to this disease $[3,5]$. A male patient who is 25-years-old with an accessory soleus muscle that demonstrated with MRI is reported.

\section{Case Report}

A 25-year-old man presented with a posteromedial mass in the left ankle over one month. The patient described the mass becoming painful after significant physical activity. And there was no special medical history to this area. Physical examination revealed a tender soft-tissue mass and swelling of the left posterior-medial ankle located just anterior to the Achilles tendon. The patient was suggested to be performed by MRI to exclude a soft-tissue tumor.

The MRI examination was performed using a 1.5T MRI unit Signa Advantage Horizon; GE Medical

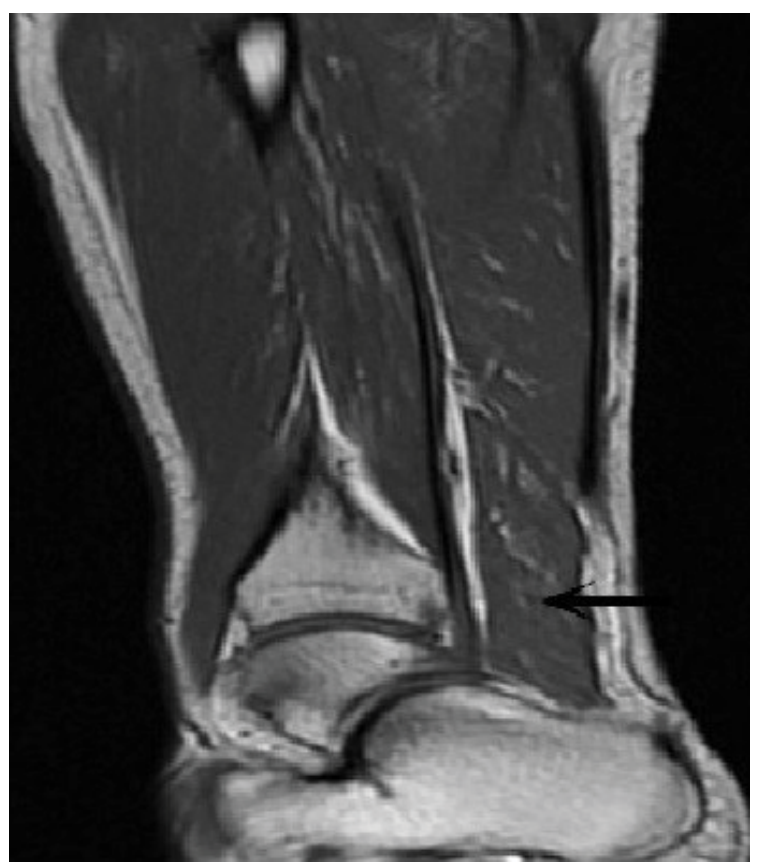

Figure 1: The T1 weighted sagittal sequence shows the mass (arrow) originating from the ventral portion of the normal soleus muscle and inserting to the medial surface of the calcaneus independently of Achilles tendon.

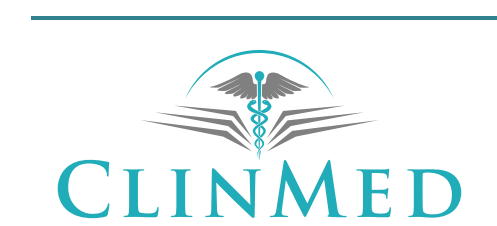

INTERNATIONAL LIBRARY
Citation: Zhang J, Hao D, Zhang C, Wang S (2019) MRI Diagnosis of Accessory Soleus Muscle: A Case Report and Review of the Literatures. Int J Foot Ankle 3:022.

Accepted: February 11, 2019; Published: February 13, 2019

Copyright: (c) 2019 Zhang J, et al. This is an open-access article distributed under the terms of the Creative Commons Attribution License, which permits unrestricted use, distribution, and reproduction in any medium, provided the original author and source are credited. 
Systems, Milwaukee, WI, USA. The T1 weighted coronal sequences showed the mass originating from the ventral portion of the normal soleus muscle and inserting to the medial surface of the calcaneus independently of Achilles tendon (Figure 1). Compared with the normal side, the affected side showed a homogeneous soft tissue mass located posteromedial to the flexor hallucis longus tendon and anteromedial to the Achilles tendon in all sequences (Figure 2, Figure 3 and Figure 4). It showed iso intense signal on all sequences (Figure 2,

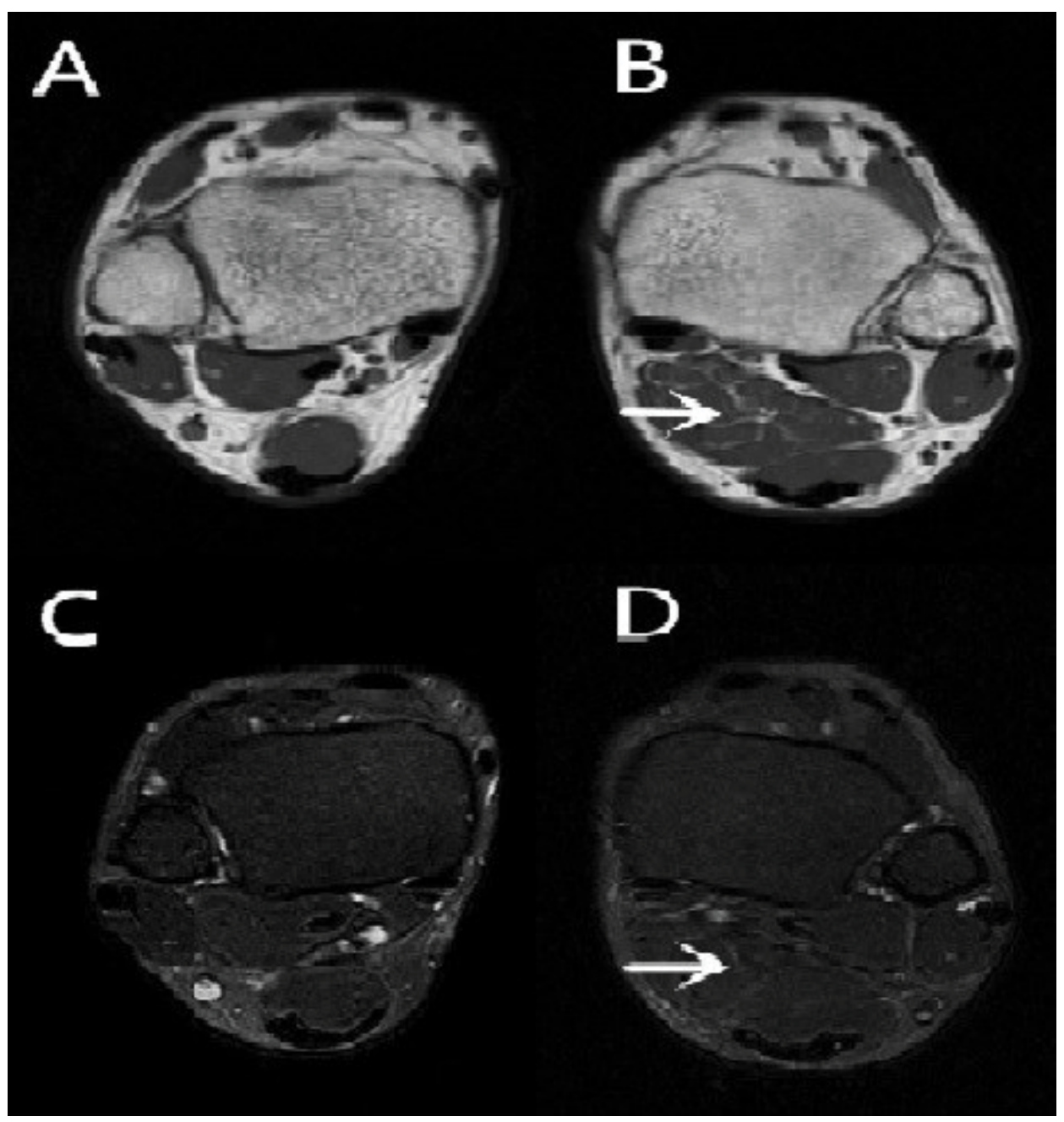

Figure 2: (B) Spin echo T1 weighted and (D) fast spin echo T2 weighted fat-suppressed axial images sequences shows that the accessory soleus muscle (arrow) had the same signal with adjacent muscles on all sequences. The $\mathrm{A}$ and $\mathrm{C}$ show the opposite side that is normal.

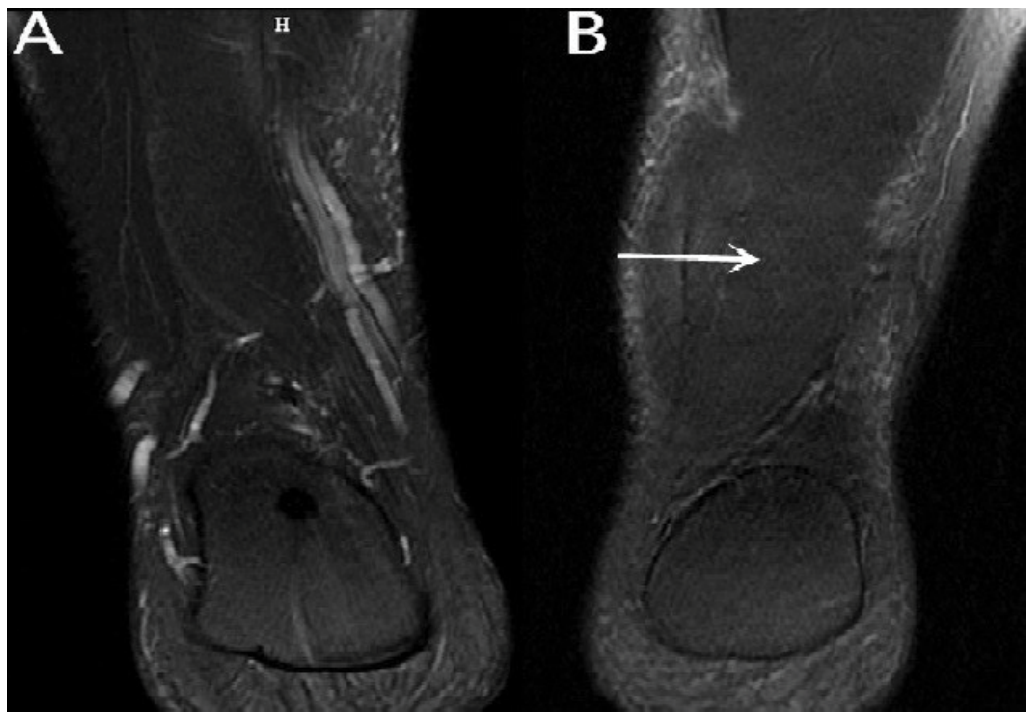

Figure 3: Fast spin echo T2 weighted fat-suppressed coronal images sequences show the differences between the both sides. 
Figure 3 and Figure 4). And the pre-Achilles' fat pad was compressed by this muscle mass. The T1-weighted sequences showed a thin rim of adipose tissue within the fascial plane around the mass (Figure 1).

From the above imaging appearance soft tissue tumor was excluded with accurate diagnosis of accessory soleus muscle. The patient was avoided from unnecessary treatment. The patient's painful symptoms had been relieved by freeing from heavy activities.

\section{Discussion}

Hatzantoniset, et al. [8] demonstrated the prevalence of the accessory soleus muscle in cadaveric specimens was $0.7-5.5 \%$, which was equivalent to the $3 \%$ prevalence of the accessory soleus muscle in imaging patients. The males were more likely to possess the unilateral accessory soleus muscle while the females possess the bilateral accessory soleus muscle. The overall prevalence of the accessory soleus muscle by gender has been found to be $2.4 \%$ in males and $2.1 \%$ in females [8]. Although there have been several clinical cases of symptomatic pain associated with the accessory soleus muscle, most individuals area symptomatic and it is an incidental finding during routine investigation [8].

The attachment sites of the accessory soleus muscle can be mainly concluded into five types in previous studies [8-10]. They include: 1-insertion along the tendon of Achilles, 2-fleshy insertion to the upper surface of the calcaneus, 3-tendinous insertion to the upper surface of the calcaneus, 4-fleshy insertion to the medial surface of the calcaneus, 5-tendinous insertion to the medial surface of the calcaneus (Figure 5). The present case shows that the insertion of the accessory soleus muscle is on the medial surface of the calcaneus along the tendon of Achilles and the root of the accessory soleus muscle is the ventral portion of the normal soleus muscle.

Although the presence of an accessory soleus muscle is not uncommon, patients are rarely symptomatic [11]. The accessory soleus muscle always manifests as a soft tissue mass in the posteromedial region of the ankle. However, it is also responsible for some congenital club foots [12-15]. And the symptomatic accessory soleus muscle always has a painful swelling in the posteromedial region of the ankle [1]. Pain in symptomatic patients is mainly due to an ischemic blood supply, compression of the tibial nerve by the accessory soleus muscle, excessive pressure on the nerve innervating the accessory soleus muscle, or a localized compartment syndrome $[1,16]$.

The accessory soleus muscle can be diagnosed by

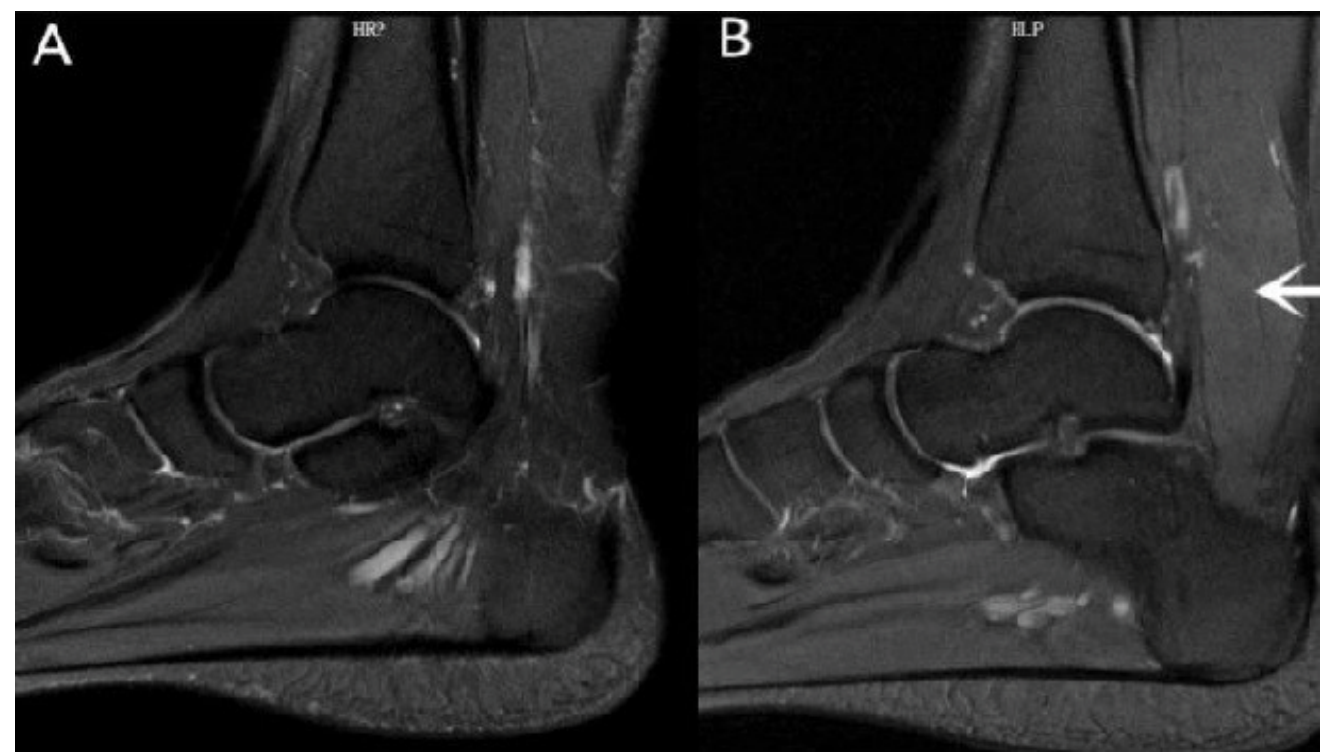

Figure 4: Fast spin echo T2 weighted fat-suppressed sagittal images show the differences between the both sides.

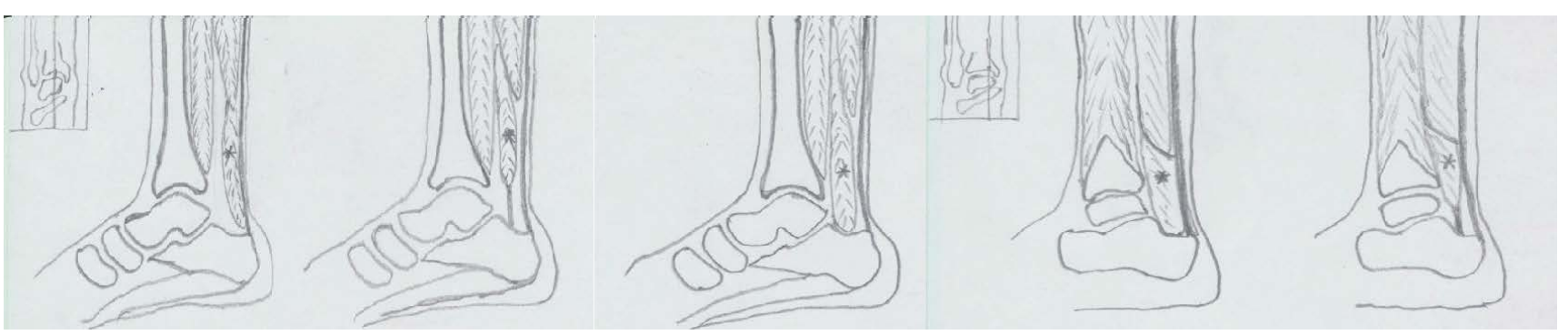

Figure 5: I: Insertion along the tendon of Achilles; II: Fleshy insertion to the upper surface of the calcaneus; III: Tendinous insertion to the upper surface of the calcaneus; IV: Fleshy insertion to the medial surface of the calcaneus; V: Tendinous insertion to the medial surface of the calcaneus. 
many methods. From the beginning it usually diagnosed by surgical exploration. The plain $x$-ray shows that the Kager's triangle is replaced by soft tissue mass. Ultrasonography can also demonstrate the extra normal muscle echotexture [7]. Computed tomography can show the exact location of the accessory soleus muscle but can hardly differentiate this variant from other soft tissues masses. MRI can lead to definite diagnosis because of the ability to discriminate the signal between normal muscle tissue and tumorous masses $[7,17]$. Furthermore, MRI can clearly define the sites of origin and insertion of the accessory soleus muscle. Currently $M R I$ is the most effective noninvasive method for a definitive diagnosis of the accessory soleus muscle.

Based on the advantages of MRI, it is more likely to differentiate the accessory soleus muscle from other soft tissue tumors in the posteromedial aspect of the ankle includes lipoma, ganglion, hemangioma, sarcoma and synovioma. The key to the differentiation from other lesions is the findings of MRI signal characteristics that are consistent with normal muscle, the main trunk of the mass and the typical anatomic location [2]. MRI scanning of the contra lateral ankle can help radiologists to get the correct diagnosis.

The therapeutic indication is based on the presence or severity of the symptoms. For asymptomatic patients, it is not necessary to treat. For the patients with moderate symptoms, conservative treatment can be proposed. However, it is essential for severe patients to perform surgical treatment [10].

\section{Conclusion}

In conclusion, the accessory soleus muscle is a congenital anatomic variation rather than soft tissue tumors. In fact, the characteristic appearance on MRI allows a confident diagnosis without the need to resort to biopsy. This case would alert radiologists to understand the lesion at this special location, and alert them to distinguish it from other soft tissue tumors. Combining with the imaging features and clinical presentation, the unnecessary damage to the patients can be avoided.

\section{References}

1. Brodie JT, Dormans JP, Gregg JR, Davidson RS (1997) Accessory soleus muscle. A report of 4 cases and review of literature. Clin Orthop Relat Res 337: 180-186.

2. Doda N, Peh WC, Chawla A (2006) Symptomatic accessory soleus muscle: Diagnosis and follow-up on magnetic resonance imaging. $\mathrm{Br} J$ Radiol 79: e129-e132.
3. Palaniappan M, Rajesh A, Rickett A, Kershaw CJ (1999) Accessory soleus muscle: A case report and review of the literature. Pediatr Radiol 29: 610-612.

4. Luck MD, Gordon AG, Blebea JS, Dalinka MK (2008) High association between accessory soleus muscle and achilles tendonopathy. Skeletal Radiol 37: 1129-1133.

5. Pla ME, Dillingham TR, Spellman NT, Colon E, Jabbari B (1996) Painful legs and moving toes associates with tarsal tunnel syndrome and accessory soleus muscle. Mov Disord 11: 82-86.

6. Assoun J, Railhac JJ, Richardi G, Fajadet P, Fourcade D, et al. (1995) CT and MR of accessory soleus muscle. J Comput Assist Tomogr 19: 333-335.

7. Bianchi S, Abdelwahab IF, Oliveri M, Mazzola CG, Rettagliata P (1995) Sonographic diagnosis of accessory soleus muscle mimicking a soft tissue tumor. J Ultrasound Med 14: 707-709.

8. Hatzantonis C, Agur A, Naraghi A, Gautier S, McKee N (2011) Dissecting the accessory soleus muscle: A literature review, cadaveric study, and imaging study. Clin Anat 24: 903-910.

9. Yildirim FB, Sarikcioglu L, Nakajima K (2011) The coexistence of the gastrocnemius tertius and accessory soleus muscles. J Korean Med Sci 26: 1378-1381.

10. Mukish P, Reybet Degat PY, Demangel A, Trouilloud $P$, Baulot E (2012) Accessory soleus muscle: A difficult diagnosis: A case report and a review of the literature. Eur J Orthop Surg Traumatol 22: 205-209.

11. Leswick DA, Chow V, Stoneham GW (2003) Resident's corner. Answer to case of the month \#94. Accessory soleus muscle. Can Assoc of Radiol J 54: 313-315.

12. Chotigavanichaya C, Scaduto AA, Jadhav A, Otsuka NY (2000) Accessory soleus muscle as a cause of resistance to correction in congenital club foot: A case report. Foot Ankle Int 21: 948-950.

13. Kishta WE, Mansour EH, Ibrahim MM (2010) The accessory soleus muscle as a cause of persistent equinus in clubfeet treated by the ponseti method: A report of 16 cases. Acta Orthop Belg 76: 658-662.

14. Gupta P, Singla R, Gupta R, Jindal R, Bahadur R (2007) Accessory soleus muscle in clubfoot deformity: A report in four feet. J Pediatr Orthop B 16: 106-109.

15. Rambani R, Shahid MS (2006) Accessory soleus muscle as a cause of congenital talipes equino varus. A case report. Acta Orthop Belg 72: 644-646.

16. John G P Williams (1996) The accessory soleus muscle. $\mathrm{Br}$ J Sports Med 30: 185-186.

17. Paul MA, Imanse J, Golding RP, Koomen AR, Meijer S (1991) Accessory soleus muscle mimicking a soft tissue tumor. A report of 2 patients. Acta Orthop Scand 62: 609611. 